\title{
Analisa dan Perancangan Aplikasi Sistem Penyewaan Kendaraan berbasis Java
}

\author{
Septi Nur Ilmi Putri ${ }^{1}$, Mohammad Zaeni2, Desi Jasmiati ${ }^{3}$, Endar Nirmala ${ }^{4}$, Irpan Kusyadi ${ }^{5}$ \\ Teknik Informatika, Universitas Pamulang, Tangerang Selatan, Indonesia, 15417 \\ e-mail: ${ }^{1}$ septinurilmi@gmail.com, ${ }^{2}$ mohamadzaeni57@gmail.com, ${ }^{3}$ dessyjasmiati@gmail.com, \\ ${ }^{4}$ dosen00216@unpam.ac.id, ${ }^{5}$ dosen00673@unpam.ac.id
}

Submitted Date: May 31 2021

Revised Date: July $05^{\text {th }}, 2021$
Reviewed Date: June $11^{\text {th }}, 2021$

Accepted Date: July 06 ${ }^{\text {th }}, 2021$

\begin{abstract}
Rental is a service provider that provides vehicle rental services. Currently, there are still many rental businesses that use manual systems for data processing which results in less efficient and slow work. Lack of information also makes it difficult for prospective tenants to find out the vehicle you want to rent. Making this application design aims to help facilitate ordering and information. This vehicle rental application will be designed using the Unified Modeling Language (UML) method, which visualizes the modeling using Use Case Diagrams and Activity Diagrams. Then the programming language that will be planned is JAVA language, with the MYSQL database as data storage. Meanwhile, the application development uses the Netbeans IDE 8.2. This system will provide results in the form of rental information and ordering transactions to facilitate vehicle rental activities.
\end{abstract}

Keywords: Application; Vehicle Rent; Information Systems; UML Method; Java

\section{Abstrak}

Rental merupakan penyedia layanan yang memberikan jasa penyewaan kendaraan. Saat ini masih banyak bisnis penyewaan yang memakai sistem manual pada pengolahan data nya yang mengakibatkan pekerjaan kurang efisien dan lambat. Informasi yang kurang juga menyulitkan calon penyewa untuk mengetahui kendaraan yang ingin di sewa. Pembuatan perancangan aplikasi ini bertujuan untuk membantu mempermudah pemesanan beserta informasinya. Aplikasi penyewaan kendaraan ini akan dirancang dengan menggunakan metode Unified Modeling Language (UML), yang mana visualisasi pemodelan nya memakai Use Case Diagram dan Activity Diagram. Lalu Bahasa pemrograman yang akan direncanakan adalah Bahasa JAVA, dengan database MYSQL sebagai penyimpanan data. Sedangkan pembuatan aplikasi nya menggunakan Netbeans IDE 8.2. Sistem ini nantinya akan menyediakan hasil berupa informasi penyewaan dan transaksi pemesanan untuk memudahkan kegiatan penyewaan kendaraan.

\section{Kata Kunci: Aplikasi; Sewa Kendaraan; Sistem Informasi; Metode UML; Java}

\section{Pendahuluan}

Salah satu yang mengalami dampak kemajuan adalah Internet. Internet bisa dipakai sebagai media pemasaran suatu bisnis untuk mempromosikan sebuah produk dari bisnis tersebut. Selain itu internet pun bisa difungsikan sebagai sarana melakukan transaksi, pemesanan dan lain sebagainya. Bisnis penyewaan atau biasa dikenal Rental, merupakan suatu usaha pada bidang jasa yang kegiatanya melakukan penyewaan dengan adanya suatu kesepakatan atau perjanjian dua pihak antara pihak yang menyewa dan pemilik barang yang disewa. Dalam pembahasaan ini yang akan di sewakan adalah kendaraan.

Aplikasi penyewaan kendaraan termasuk salah satu kegiatan pengolahan data yang berkaitan dengan aktivitas pencatatan dan penginputan data kendaraan. Saat ini ternyata masih banyak bisnis penyewaan kendaraan yang menggunakan sistem manual. Sebagaimana yang dibahas (Nurhayati \& Sugiarto, 2020), di mana 
segala proses pengolahan data sampai proses transaksi dilakukan pencatatan langsung di buku. Dan (Angellia, Cahya, \& Louis, 2020), sistem manual tersebut membuat data tidak rapih dan tidak terstruktur. Selain itu, kadang penyewa sulit mengetahui apakah di tempat rental tersebut ada atau tidak kendaraan untuk disewakan atau kendaraan sewa yang sesuai dengan kebutuhan, karna kendala tidak ada sistem informasi pada tempat usaha tersebut.

(Kurniawan \& Irsyadi, 2021), dibutuhkan integrase database sistem informasi sehingga dapat melakukan pertukaran data menyangkut aktivitas penyewaan kendaraan. Pembuatan sistem informasi ini dimaksudkan untuk memudahkan para calon klien penyewa dalam mengakses informasi seputar penyewaan kendaraan. Selain itu, calon penyewa dapat melakukan pemesanan awal penyewaan kendaraan. Keamanan dalam proses penyimpanan data juga terjamin sehingga bisa meminimalisir kerusakan data, kehilangan data dan pencurian data karena memiliki hak akses mengelola sistem itu.

Solusi permasalahan tersebut adalah menggunakan sebuah sistem aplikasi basis data, yang mana pengolahan datanya meliputi data penyewa, data kendaraan yang disewa, transaksi penyewaan, transaksi pengembalian kendaraan, dan juga data informasi seputar penyewaan tersebut. Untuk pembuatan aplikasinya akan menerapkan metode DFD (Data Flow Diagram), di mana sebuah diagram yang akan mengilustrasikan setiap alur hubungan antarbagian file. Untuk pengembangan desain manajemen sistem penyewaan ini akan di rancang menggunakan metode UML.

Selain itu, sistem ini juga akan menggunakan metode SDLC (System Development Life Cycle) atau bisa diartikan sebagai siklus hidup pengembangan sistem. Penggunaan SDLC dimaksudkan untuk mengembangan suatu sistem agar dapat dijalankan baik sesuai yang direncanakan, mulai dari perencanaan kebutuhan, analisis dan rancangan desain sistem, implementasi, pengetesan, perawatan hingga kebijakan perencanaan sistem atau penyerahan kepada penyewa (Budiarto, 2016). Lalu akan membuat Aplikasi Sistem Penyewaan Kendaraan Berbasis Java dengan menggunakan Netbeans IDE 8.2. Sistem bertujuan mempermudah proses penyewaan dan transaksi bisnis tersebut.

\section{Metodologi}

Sistem informasi penyewaan kendaraan ini dirancang dengan menggunakan metode UML (Unified Modeling Language). UML merupakan salah satu bahasa permodelan secara visualisasi dalam rancangan pengembangan sistem yang berorientasi objek. Ini dikarenakan bahasa yang disediakan metode UML ini memungkinkan pengembang sistem membuat skema yang relevan pada konsep rancangan dengan bentuk yang mudah di pahami, juga dilengkapi mekanisme untuk berbagi rancangan (sharing) secara efektif. Selain itu, rancangan juga dapat dikomunikasikan dengan yang lain. Sun Microsystem Inc, (Budiarto, 2016) UML merupakan bahasa grafis yang berfungsi menggambarkan dan mendokumentasikan alur desain dan hasil analisa yang merepresentasikan kebutuhan pada suatu sistem. Diagram grafis dalam metode UML terbagi beberapa jenis, diantara nya ada use case diagram dan activity diagram.

Tahapan-tahapan yang akan dilakukan dalam mendukung pengembangan perancangan sistem Penyewaan Kendaraan ini di antaranya, menganalisis kebutuhan perangkat lunak, perancangan (design), pembuatan program, pengujian lalu penerapan. Berikut ini penjelasannya:

a) Analisa kebutuhan perangkat lunak Di sini akan melakukan pengumpulan data dengan mengutamakan sistem dalam perangkat lunak seperti informasi, penjelasan masing-masing setiap bagian sistem, cara kerja dan interface, lalu menyediakan cara penyelesaian untuk membantu penentuan kebutuhan melalui sistem penyewaan dalam menjalankan pengolahan data.

b) Perancangan Design

Di sini akan membentuk perancangan alur data, arsitektur sistem perangkat lunak, rincian proses dari setiap intruksi yang diminta atau prosedural. Karakteristik interface akan dirancang di setiap tampilan layar seperti form masukan dan keluaran.

c) Pembuatan Program (Coding)

Ditahap ini akan membuat coding sesuai dengan design yang dirancang yang merupakan tahap untuk membuat program aplikasi agar dapat digunakan.pembuatan kode program mengunakan bahasa pemograman java.

d) Pengujian 
Pada tahap ini aplikasi akan diuji untuk memeriksa apakah aplikasi bisa dipakai dengan baik atau masih terdapat kekurangan/kesalahan. Pengujian terhadap perangkat lunak sangat penting dilakukan dengan tujuan untuk memberikan jaminan kualitas perangkat lunak yang dihasilkan agar bebas dari terjadinya kesalahan (Debiyanti, Sutrisna, Budrio, Kamal, \& Yulianti, 2020). Pengujian software untuk melakukan verifikasi dan validasi bahwa software yang telah dibuat sesuai dengan kebutuhan (Jaya, Gumilang, Wati, Andersen, \& Desyani, 2019). Untuk rangkaian pengujian ini dijalankan sekaligus berdasarkan data aktual dari proses yang telah ada atau sistem yang sedang beroperasi.

e) Maintance (implementasi)

Tahapan ini merupakan bagian terujung dari perancangan sistem penyewaan kendaraan. Tujuan tahapan ini yaitu untuk melakukan pemeriksaan untuk mengetahui jika terdapat kesalahan pada perangkat lunak saat sedang dipergunakan user.

\section{Hasil dan Pembahasan}

Use case diagram merupakan salah satu dari diagram UML, berfungsi sebagai gambaran rancangan fasilitas sistem yang tersedia untuk user. Pembuatan use case diagram ini dimaksudkan untuk mengetahui fungsi apa saja yang ada dalam sebuah sistem. Use Case diagram mendeskripsikan hubungan atau interaksi antara aktor (pelaku) dan sistem. Aktor disini merupakan pelaku yang biasa di representasikan sebagai manusia atau alat komunikasi lain yang berhadapan dengan sistem untuk melakukan interaksi terkait suatu perintah tertentu di dalam aplikasi.

\section{Use Case Diagram Sistem Penyewaan Kendaraan}

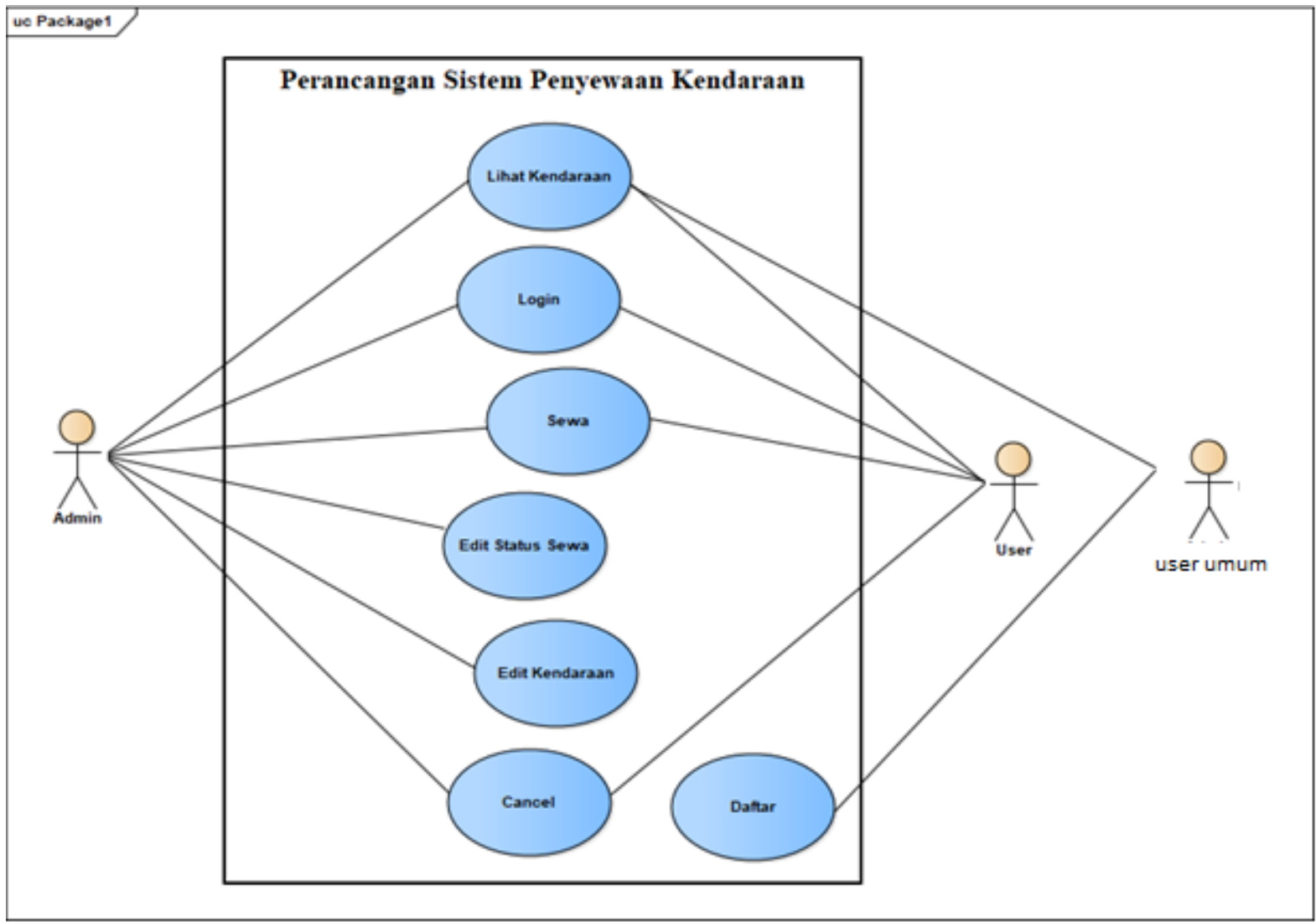

Gambar 1 Use Case Diagram Sistem Penyewaan Kendaraan 
Pada Gambar 1 dijelaskan apa yang bisa di operasikan oleh admin, user dan user umum. Operasi yang tercantum pada interface ini diantaranya, lihat kendaraan, login, sewa, edit status sewa, edit kendaraan, cancel dan daftar. Untuk admin dapat mengakses semua perintah itu kecuali daftar. User dapat mengakses perintah lihat kendaraan, login, sewa dan cancel. Sedangkan user umum hanya dapat mengakses pilihan lihat kendaraan dan informasi yang tertera pada tampilan layer, atau bisa mengakses daftar untuk menjadi user.

\section{Activity Diagram}

Activity diagram merupakan gambaran setiap alur aktivitas dan tindakan dalam sistem perancangan, dari bagaimana aliran dimulai, menentukan keputusan (decision) yang akan terjadi, lalu akhir dari aliran tersebut. Komponen dalam activity diagram dipaparkan dengan bentuk tertentu yang terhubung oleh tanda panah. Panah ini akan menggambarkan setiap urutan aktivitas yang terjadi dan bagaimana arahnya. Sebuah aktivitas dapat dibuat berdasarkan oleh satu use case atau lebih.

Berdasarkan use case pada gambar di atas, berikut adalah rancangan diagram aktivitasnya.

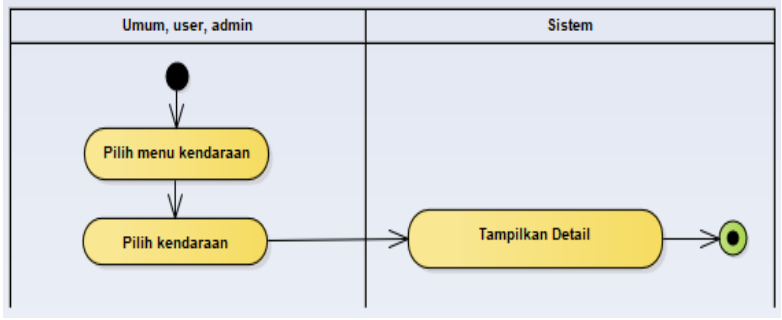

Kendaraan

Gambar 2 Activity Diagram Lihat

Pada gambar di atas dijelaskan bahwa pengguna umum, user dan admin dapat melihat detail informasi dari kendaraan yang akan disewa, dengan memilih menu kendaraan dilanjutkan dengan memilih kendaraan yang diminati. Setelahnya maka sistem akan menampilkan detail informasi terkait kendaraan yang dipilih.

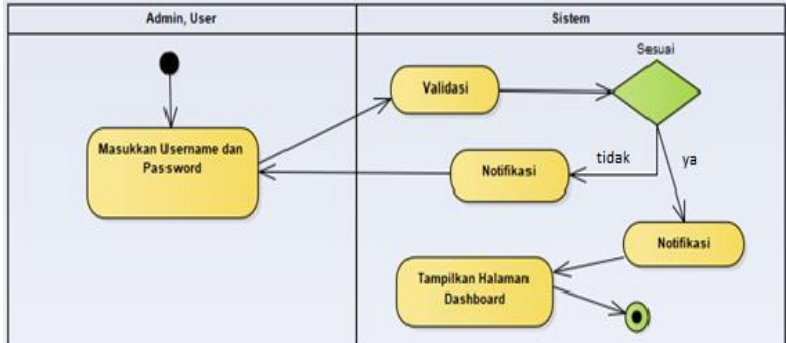

Gambar 3 Activity Diagram Login

Pada case login, aktivitas diagram nya menjelaskan bagaimana alur login yang dilakukan oleh admin dan user. Pertama, aktor akan menginput username dan password yang sebelumnya sudah mereka cantumkan saat mendaftar. Kemudian sistem akan melakukan validasi terhadap inputan. Jika sesuai, maka akan muncul notifikasi login berhasil dan sistem akan menampilkan halaman dashboard. Apabila salah atau tak sesuai, maka muncul notifikasi salah dan sistem akan mengembalikan tampilan pada menu login.

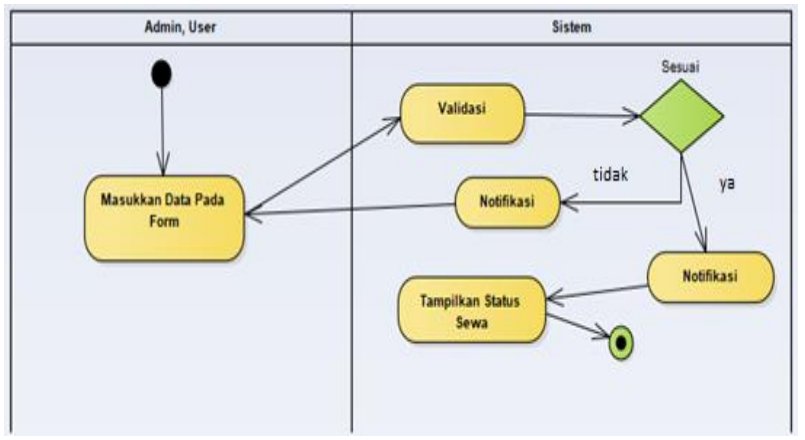

Gambar 4 Activity Diagram Sewa

Gambar 4 menunjukan bagaimana admin dan user yang telah berhasil melakukan login, dapat melakukan aktivitas sewa. Pada case 'sewa', aktor memulai dengan memasukkan data pada form yang tersedia dan diisi dengan tepat. Langkah selanjutnya sistem akan melakukan validasi untuk membuat decision. Jika data form telah terisi semua dan sesuai dengan format, maka status sewa akan ditampilkan. Apabila gagal karena ada yang terisi atau tidak sesuai format, maka akan muncul notifikasi gagal dan sistem akan mengembalikan tampilan ke menu pengisian form untuk dilakukan pengisian data yang salah atau masih kosong. 


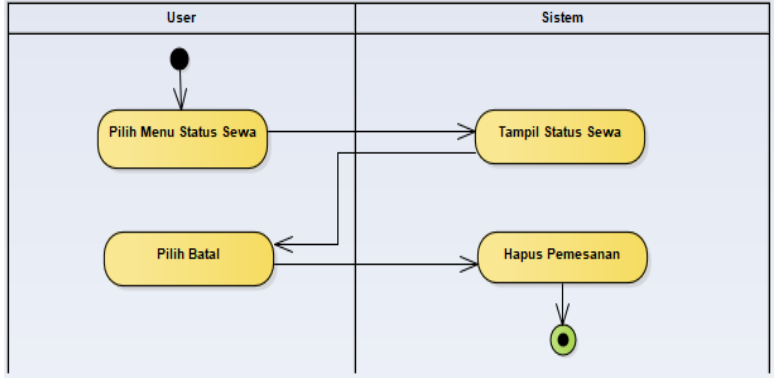

Gambar 5Activity Diagram Batal Sewa

Aktivitas diagram di sini menggambarkan bagaimana alur saat melakukan batal sewa. Aktor dalam case ini yaitu user, akan memilih menu status sewa yang mana selanjutnya sistem akan menampilkan halaman status sewa. User lalu memilih perintah batal dan secara otomatis sistem akan menghapus pemesanan yang telah dipilih user untuk dibatalkan.

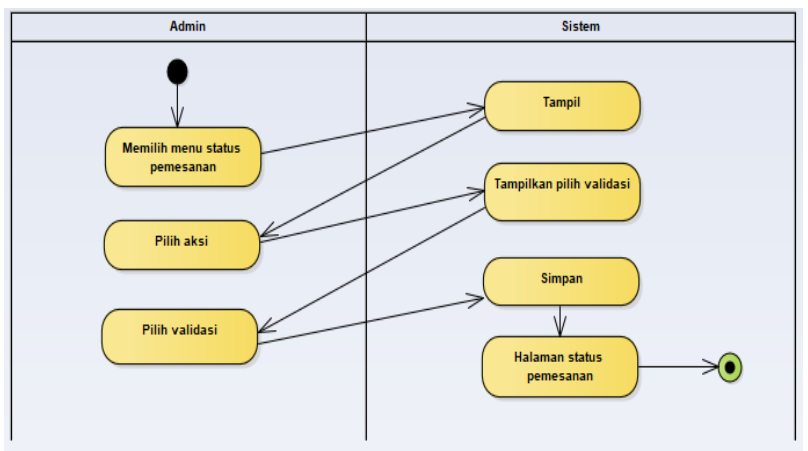

\section{Gambar 6 Activity Diagram Edit Status Pemesanan}

Gambar 6 menerangkan proses dari aktivitas edit status pemesanan. Aktor dalam case ini hanya admin. Disini dimulai dengan memilih menu status pemesanan yang dilakukan admin, kemudian sistem mengolah perintah dengan menampilkan halaman status pemesanan. Pada halaman tersebut, admin akan memilih perintah aksi dan secara otomatis sistem menampilkan halaman pilih validasi. Validasi akan dipilih lagi oleh admin lalu memberi perintah simpan. Pilihan validasi admin akan tersimpan otomatis dan sistem akan menampilkan halaman status pemesanan.

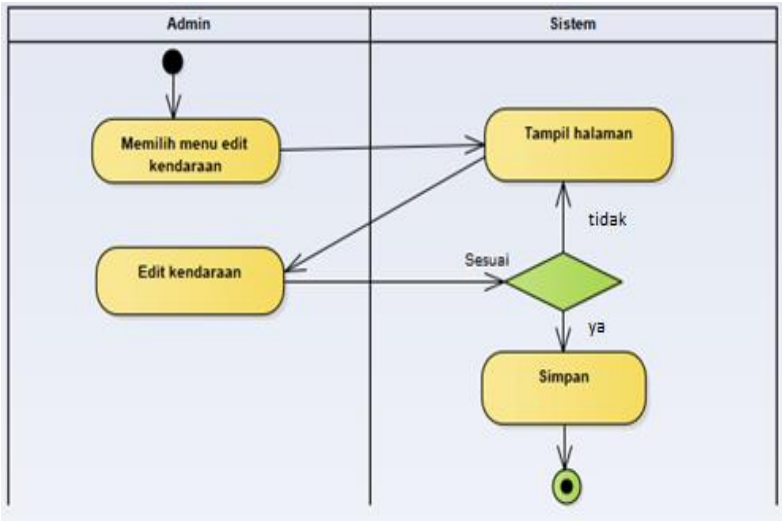

Gambar 7 Activity Diagram Edit Kendaraan

Menjelaskan bahwa admin melakukan aktivitas edit kendaraan. Akan dimulai dengan admin sebagai aktor memilih menu edit kendaraan. Setelah itu sistem akan menampilkan halaman edit kendaraan. Di halaman ini akan terdapat pilihan edit kendaraan yang menjadi langkah aktivitas selanjutnya, admin akan memilih kendaraan yang ingin diubah dan sistem merespon dengan menampilkan keterangan kendaraan yang diubah. Akan ada form yang harus diisi dan apabila isiannya sesuai, maka pilih simpan dan sistem akan menyimpan perubahan tersebut.

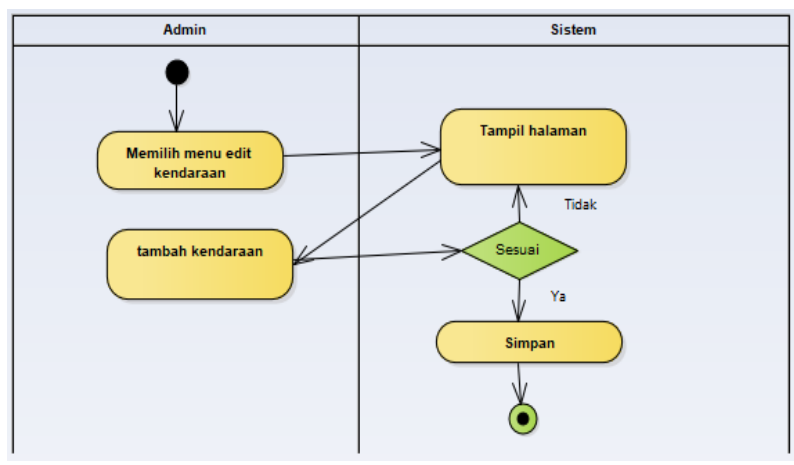

Gambar 8 Activity Diagram Tambah Kendaraan

Aktivitas diagram case 'Tambah Kendaraan' menerangkan saat admin sebagai aktor akan melakukan aktivitas menambah kendaraan yang ingin disewa. Langkah pertamanya yaitu admin akan memilih menu edit kendaraan pada halaman awal. Kemudian sistem akan pindah halaman ke halaman tambah kendaraan. Admin kemudian memilih menu tambah kendaraan, setelahnya sistem akan menampilkan form isian. Tentu harus diisi dengan 
sesuai agar decision sistem berhasil dan intruksi penyimpanan tambahan barang juga berhasil. Jika masih ada keliru atau form masih kurang yang terisi, notifikasi akan muncul lalu sistem akan kembali pada tampilan halaman pengisian form tambah kendaraan.

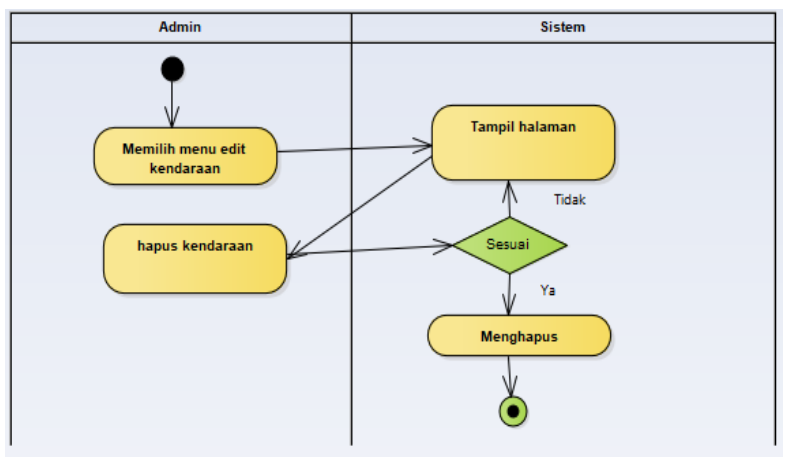

Gambar 9 Activity Diagram Hapus Kendaraan

Menjelaskan aktivitas untuk hapus kendaraan. Admin sebagai aktor memulai aktivitas dengan memilih menu edit kendaraan, lalu sistem meresponnya dengan menampilkan halaman yang dituju. Selanjutnya admin akan memilih kendaraan yang ingin dihapus pada perintah 'hapus kendaraan'. Sistem akan melakukan decision dengan memunculkan notifikasi pilihan ya atau tidak untuk dihapus. Jika pilihannya tidak maka akan kembali ke halaman edit kendaraan, jika ya maka sistem akan menghapus data kendaraan yang diajukan.

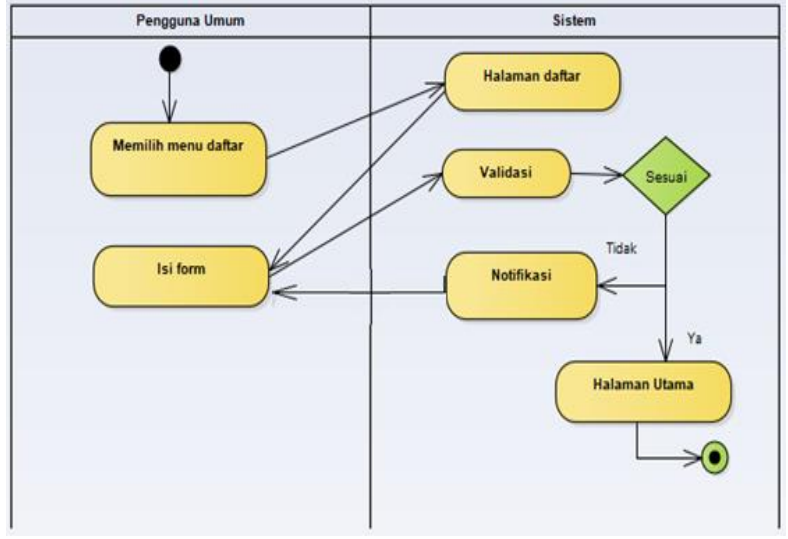

Gambar 10 Activity Diagram Daftar

Menerangkan aktivitas saat melakukan daftar yang dilakukan oleh pengguna umum sebagai aktor diagram aktivitas ini. Pertama, user umum akan memilih menu daftar dan sistem akan menampilkan halaman pendaftaran. Berikutnya user umum akan mengisi form sesuai data yang tertera untuk diperlukan. Sistem akan melakukan validasi jika telah selesai mengisi form, kalau masih ada yang kurang atau tidak sesuai maka akan muncul notifikasi pemberitahuan. Jika sudah valid pendaftarannya, maka sistem akan menuju ke halaman utama untuk melakukan login.

\section{Kesimpulan}

Perancangan sistem aplikasi penyewaan kendaraan ini disimpulkan bisa membuat segala aktivitas yang berhubungan dengan pembuatan aplikasi menjadi lebih mudah. Dengan adanya rancangan, maka programmer, dan penguji dapat mengacu ke rancangan agar tidak terjadi kesalahan.

Aplikasi ini diharapkan dapat memudahkan dalam melakukan transaksi atau menemukan informasi terkait kendaraan yang akan disewa. Validasi pemesanan dilakukan oleh admin untuk menentukan calon penyewa/user diterima atau tidak. Sedangkan pengguna umum hanya bisa mengakses untuk melihat informasi kendaraan sewa saja. Aplikasi ini diharapkan dapat mempermudah kegiatan dan aktivasi kegiatan penyewaan ini yang memang perlu kecepatan dan ketetapan informasi. Penerapan aplikasi sistem informasi penyewaan berbasis java ini diharapkan dapat menjadi bagian dari langkah maju dalam perkembangan teknologi informasi.

\section{Referensi}

Almantara, I. P., Wiranatha, A. A., \& Wibawa, K. S. (2017). Sistem Informasi Penyewaan Kendaraan Bermotor Customer to Customer (C2C). Jurnal Ilmiah Merpati (Menara Penelitian Akademika Teknologi Informasi), 5(3), 219-227. doi:10.24843/JIM.2017.v05.i03.p07

Angellia, F., Cahya, W., \& Louis, P. J. (2020, Oktober). Perancangan Sistem Informasi Penyewaan Mobil Berbasis Java Pada Rental Mobil XYZ. Jurnal Sistem Informasi Bisnis, 1(2), 80-88.

Ardiana, H., Alfarisi, S., \& Hapsari, A. T. (2021). Perancangan Sistem Aplikasi Penyewaan Bus Pariwisatan Berbasis JAVA Pada PT Djess Berkah Wisata. Jurnal Riset dan Aplikasi Mahasiswa Informatika (JRAMI), 2(1), 135141. doi:10.30998/jrami.v2i01.1120

Budiarto, I. (2016). Sistem Informasi Persewaan Mobil Berbasis WEB Menggunakan Metode UML. Surakarta.

Debiyanti, D., Sutrisna, S., Budrio, B., Kamal, A. K., \& Yulianti, Y. (2020). Pengujian Black Box 
pada Perangkat Lunak Sistem Penilaian Mahasiswa Menggunakan Teknik Boundary Value Analysis. Jurnal Informatika Universitas Pamulang, 5(2), 162-166. doi:10.32493/informatika.v5i2.5446

Derian, P., \& Nina, S. (2019). Rancang Bangun Sistem Informasi Penyewaan Kendaraan Berbasis Web. Jurnal Sistem Informasi dan Sains Teknologi, 1-9.

Heriyanto, Y. (2018, Oktober). Perancangan Sistem Informasi Rental Mobil Berbasis Web Pada PT. APM RENT CAR. 2.

Jaya, M. S., Gumilang, P., Wati, T., Andersen, Y. P., \& Desyani, T. (2019). Pengujian Black Box pada Aplikasi Sistem Penunjang Keputusan Seleksi Calon Pegawai Negeri Sipil Menggunakan Teknik Equivalence Partitions. Jurnal Informatika Universitas Pamulang, 4(4), 131136. doi:10.32493/informatika.v4i4.3834

Kurniawan, A., Abadi, L. P., \& Wilson, A. (2020). Perancangan Sistem Informasi Penyewaan Bus Pariwisata di Rizky Jaya Transport Berbasis Java. Jurnal Riset dan Aplikasi Mahasiswa Informatika (JRAMI), 01(1), 1 - 7.

Kurniawan, D. W., \& Irsyadi, F. Y. (2021, Maret). Perancangan dan Pembuatan Aplikasi Manajemen Peminjaman Kendaraan Berbasis Web Dengan Framework Condeigniter. Jurnal Teknik Elektro, 21(1), 1-5.

Nurhayati, W., \& Sugiarto, H. (2020, Mei). Aplikasi Sistem Informasi Penyewaan Motor Berbasis Desktop. Journal Speed - Sentra Penelitian Engineering dan Edukasi, 12(2), 1 - 5.

Wahyudi, J. (2019). Pembangunan Sistem Aplikasi Penyewaan Mobil Berbasis Android Studi Kasus : CV. Amanah Kalimantan Rent. Journal of Industrial Engineering and Operation Management (JIEOM), 2(1), 10-16. doi:10.31602/jieom.v2i1.2082

Y, E. Y., \& Dhika, H. (2021, January). Sistem Informasi Manajemen Rental di PT Mobil GO Rental. Semnas Ristek (Seminar Nasional Riset dan Inovasi Teknologi), 1292-1297. 